\title{
O PERFIL E O CRESCIMENTO ECONÔMICO AGROPECUÁRIO DA REGIÃO SUL DO BRASIL ENTRE 1996 E 2010'
}

\author{
THE PROFILE AND THE AGRICULTURAL ECONOMIC \\ GROWTH IN SOUTHERN BRAZIL BETWEEN 1996 AND 2010
}

\author{
Isabela Barchet \\ Universidade Estadual do Oeste do Paraná - Toledo - PR - Brasil \\ Jandir Ferrera de Lima \\ Universidade Estadual do Oeste do Paraná - Toledo - PR - Brasil
}

\begin{abstract}
Resumo: $O$ artigo analisa o perfil e o crescimento econômico agropecuário dos estados da Região Sul do Brasil no início do século XXI. Para tanto, foram desenvolvidos indicadores referentes ao setor agropecuário, que, de um modo geral, apoiam-se no Quociente Locacional (QL), no Índice do Nível de Crescimento Agrícola (INC) e no índice do ritmo de crescimento agrícola (IRC). Os resultados apresentam que o processo de crescimento econômico agrícola da região foi dinâmico em todos os estados, porém, com uma economia agrícola deprimida. Reflexo do processo de agroindustrialização que, nas últimas duas décadas, foi potencializado pela maior abertura comercial e pela ampliação do mercado interno em razão da estabilidade macroeconômica. $O$ indicador do ritmo de crescimento econômico agrícola classifica o Estado de Santa Catarina e do Rio Grande do Sul como de crescimento agrícola recessivo e o Estado do Paraná como de crescimento agrícola depressivo.
\end{abstract}

Palavras-chave: Produção Agrícola. Economia Regional. Indicadores Econômicos.

Abstract: This paper analyzes the profile and the agricultural economic growth in Southern Brazil, in the beginning of the XXI century. For this, the article applies indicators for the agricultural sector, such as the location quotient (QL), the index level of agricultural growth (INC) and the index of the rhythm of agricultural growth (IRC). The results show that the process of the Region's agricultural economic growth was dynamic in all states, but with a depressing agricultural economy. Reflection of agricultural industrialization process, which the last two decades, augmented in reason of greater trade openness, expansion of the internal market and economic stability. The indicator of the rhythm of agricultural economic growth classifies the State of Santa Catarina and Rio Grande do Sul as recessive agricultural growth and the state of Paraná as depressing agricultural growth.

Key Words: Agricultural Production. Regional Economy. Economic indicators.

\section{INTRODUÇÃO}

O artigo analisa o crescimento econômico e o perfil agropecuário dos estados da Região Sul do Brasil no início do século XXI. O crescimento econômico é a expansão do produto da economia ao longo do tempo. No âmbito do setor

\footnotetext{
${ }^{1}$ Esse texto é baseado em pesquisa financiada pela Fundação Araucária (PR) e o Conselho Nacional de Desenvolvimento Científico e Tecnológico (CNPQ).
} 
agropecuário, sua análise permite caracterizar a dimensão econômica agropecuária nos estados da Região Sul do Brasil (JUNQUEIRA; STERCHILE; FERRERA DE LIMA, 2009; SPEROTTO; SOUZA, 2005). Além disso, a análise da expansão da produção das principais commodities ao longo do tempo e a caracterização do perfil agropecuário dos estados da Região Sul torna-se relevante a fim de caracterizar as especificidades e a dinâmica da região em estudo.

Desde o início dos anos 1990, o agronegócio brasileiro se depara com a necessidade de aumentar seu nível de competitividade, de modo a alterar sua característica básica de ser competitivo apenas em commodities e incipiente em ramos agroindustriais. Dessa forma, a partir do recorte temporal adotado, este estudo analisa a dinâmica do setor agropecuário da Região Sul do Brasil, dentro dessa nova moldura, bastante diferente dos padrões vigentes até o final da década de 1980. Portanto, torna-se relevante considerar indicadores referentes à produção agropecuária para que seja possível identificar o cenário agropecuário dos estados da Região Sul do Brasil após a abertura econômica e a estabilização monetária do país.

Para tanto, cinco seções são apresentadas, além desta breve introdução. A seção 2 apresenta um sucinto aporte teórico alicerçado na localização de atividades econômicas. A seção 3 expõe o referencial analítico deste estudo ao descrever o procedimento adotado para a obtenção dos resultados que, de um modo geral, apoiam-se no $\mathrm{QL}$, no INC e no IRC. A seção 4 caracteriza, brevemente, o perfil agropecuário dos estados da Região Sul. A seção 5 enfatiza a dinâmica do crescimento econômico dos estados a partir da análise de indicadores referentes ao setor agropecuário. Por fim, apresentam-se as principais conclusões do crescimento econômico e perfil agropecuário dos estados da Região em estudo.

\section{A DINÂMICA DA ECONOMIA REGIONAL}

As mudanças verificadas na economia nas últimas duas décadas modificaram a forma de produzir e as estratégias de localização das atividades econômicas. Para Alves (2012), a teoria econômica tradicional ignorava os aspectos espaciais em seus estudos. Porém, ao longo do tempo, as questões de localização e de espaço foram incorporadas à teoria econômica. O crescente interesse em relação aos problemas locacionais e regionais, indiscutivelmente, deve-se às suas implicações políticas, embora os problemas espaciais sejam dignos de estudos por si mesmos.

Nessa perspectiva, os estudos sobre localização das atividades econômicas são de grande importância, via de regra, são responsáveis pela repartição equilibrada das atividades no espaço (ALVES, 2012). É nesse contexto que as medidas de localização e de especialização ganham sua importância. Conforme Paiva (2006), a especialização de uma região é tida como condição de desenvolvimento e, além disso, a especialização é um importante "indício" do potencial de uma região e, consequentemente, do seu crescimento econômico. 
As medidas de localização se referem à natureza setorial entre as distintas regiões, bem como à determinação das especializações das mesmas. Elas se concentram na localização espacial das atividades econômicas e nas mudanças espaciais ao longo do tempo, assim como nos padrões de concentração ou dispersão espacial dessas atividades. No contexto deste estudo, Vieira Filho, Campos e Ferreira (2005) corroboram que as medidas de localização permitem descrever padrões de comportamento das atividades produtivas agrícolas no espaço econômico e também padrões diferenciais de estruturas produtivas agrícolas entre várias regiões.

De modo geral, o desempenho dos setores produtivos dos estados tende a acompanhar os respectivos desempenhos no âmbito nacional. Porém, as disparidades regionais oriundas do movimento do capital caracterizam um processo de maximização do potencial de uma região, ou seja, o capital se aloca em regiões tentando aproveitar-se de algumas variáveis que são fundamentais para a geração de economias de escala (JUNQUEIRA; STERCHILE; FERRERA DE LIMA, 2009).

Para Ferrera de Lima e Eberhardt (2010), a região, para seu desenvolvimento, deve criar empregos, preservar os recursos naturais e garantir condições de vida para a população. Da mesma forma, as atividades produtivas devem ser capazes de ampliar os investimentos, caso contrário a região corre o risco de cair no ostracismo econômico, que se reflete através do baixo dinamismo econômico. A relação entre agricultura e desenvolvimento econômico é intrínseca, pois ela pode exercer fortes efeitos de encadeamento para o resto da economia.

Isso inclui os investimentos no setor primário, pois, para Sperotto e Souza (2005) a ideia é a de que o crescimento agrícola provoca um "crescimento mais do que proporcional do resto da economia", por meio do efeito multiplicador. Então, haveria uma "mudança estrutural", no qual a participação do produto agropecuário no produto total cairia no longo prazo, apesar de seu dinamismo. Entretanto, segundo Ferrera de Lima e Koeler (1998), a agricultura apresenta três importantes funções: fornecer produtos destinados ao consumo interno; liberação de mão de obra rural para outros setores da economia e; suprir as necessidades de bens de capital e intermediário de produção externa, permitindo a geração de divisas.

A próxima seção apresenta o procedimento metodológico adotado para o desenvolvimento do estudo e, assim, possibilitando a discussão do perfil e do crescimento econômico agropecuário na Região Sul do Brasil entre 1996 e 2010.

\section{REFERENCIAL ANALÍTICO}

No intuito de analisar o crescimento econômico agropecuário dos estados da Região Sul do Brasil, entre 1996 e 2010, procurou-se, de um lado, realizar uma breve caracterização das áreas rurais destes estados, visando identificar o perfil agropecuário dos mesmos e, por outro, obter uma análise com métodos regionais, 
por meio de indicadores de localização da produção agrícola, de nível de crescimento e de ritmo de crescimento econômico agropecuário.

Para Vieira Filho, Campos e Ferreira (2005), no estudo regional, por meio de uma avaliação de indicadores econômicos, procura-se determinar padrões tanto do crescimento agrícola quanto de sua regionalização, o que torna possível a identificação de regiões dinâmicas e passivas em termos de crescimento.

Diante disso, para melhor entender os padrões estaduais do crescimento econômico agropecuário da região estudada, utilizou-se o cálculo do $\mathrm{QL}$, indicador que busca explicar o grau de concentração das atividades produtivas do setor primário no espaço econômico. A variável-base adotada neste estudo para o cálculo do QL é a quantidade produzida de grãos pelos estados da Região Sul, especificamente: arroz, café, feijão, milho, soja, sorgo e trigo.

A escolha por essa variável-base evita o cálculo do QL por valor da produção, o qual destoaria do objetivo de verificar a concentração das atividades agrícolas. A identificação da concentração das atividades agrícolas permitirá inferências sobre o possível crescimento agropecuário alicerçado em apenas alguns produtos, ou seja, a especialização de um estado em poucos produtos agropecuários, sendo estes considerados como decadentes no contexto macroeconômico, direcionando-o para um crescimento econômico pouco satisfatório.

O QL compara a participação percentual de um estado em uma atividade específica com a participação percentual do mesmo Estado no total produzido da economia regional, conforme equação (1). Valores superiores a 1 denotam indício de que o estado é relativamente mais importante, no contexto regional, em termos da atividade, do que em termos gerais de todos as atividades. Caso contrário, valores inferiores a 1 apresentam que o estado é relativamente menos importante em comparação à produção regional (HADDAD, 1989; VIEIRA FILHO; CAMPOS; FERREIRA, 2005).

$$
Q L_{i j}=\frac{\left(\frac{X_{i j}}{X_{i z}}\right)}{\left(\frac{X_{j}}{X_{z}}\right)}
$$

Sendo:

$Q L_{i j}=$ quociente locacional da atividade ino estado $j ;$

$X_{i j}=$ a produção $i$ do estado j;

$X_{i z}=$ a produção $i$ da macrorregião em estudo;

$X_{j}=$ a produção agrícola total do estado j;

$X_{z}=$ a produção agrícola total da macrorregião $z$ em estudo. 
Segundo Vieira Filho, Campos e Ferreira (2005), embora haja limitações no escopo analítico desse indicador, a sua utilização se justifica em trabalhos de natureza exploratória e em associação com outras técnicas de trabalho. As limitações podem ser técnicas ou conceituais. As limitações técnicas comuns a quase todos os métodos de análise regional relacionam-se com problemas de agregação das variáveis em níveis regionais e setoriais (ALVES, 2012). Os resultados dos indicadores são sensíveis ao tipo de agregação setorial $e$, nesse sentido, os padrões encontrados por essas medidas estão condicionados aos processos classificatórios iniciais.

Para estimar o nível de crescimento econômico agropecuário $\left(\mathrm{INC}_{\text {agro }}\right.$ ) apresentado por cada um dos estados da Região Sul, utilizou-se um indicador baseado no Valor Adicionado Bruto (VAB) per capita agropecuário de cada um deles. O Valor Adicionado representa a contribuição de determinada atividade econômica para a composição do Produto Interno Bruto (PIB). O VAB per capita agropecuário foi obtido por meio da razão entre o VAB agropecuário de cada estado em 1996 e 2010 e a população rural dos respectivos estados em 1996 e 2010.

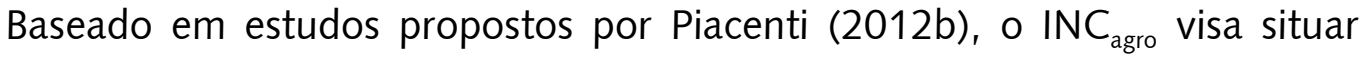
cada estado em relação ao VAB per capita agropecuário médio da macrorregião em análise, por meio da equação (2):

$$
I N C_{\text {agro }}=\left(\frac{V A B_{p c i}}{V A B_{p c m}}\right) \times 100
$$

Sendo:

$V A B_{p c i}=\mathrm{VAB}$ per capita agropecuário do estado i;

$V A B_{\mathrm{pcm}}=\mathrm{VAB}$ per capita agropecuário médio macrorregional.

A determinação do ritmo de crescimento econômico agropecuário (IRC agro $_{\text {) }}$ ) dos estados da macrorregião estudada deu-se a partir da construção, para cada estado, de um indicador relativo ao VAB per capita agropecuário médio da região em estudo (PIACENTI, 2012b). Para tanto, utilizou-se a equação (3):

$$
I R C_{\text {agro }}=\frac{\left[\left(\frac{\pi}{\Psi}\right)\right]}{\left[\left(\frac{\kappa}{\Phi}\right)\right]} \times 100
$$

Sendo:

$\pi=V A B_{p c} 1996_{i}=\mathrm{VAB}$ per capita agropecuário do estado $i$ em 1996;

$\Psi=V A B_{p c} 2010_{i}=$ VAB per capita agropecuário do estado $i$ em 2010; 


$$
\begin{aligned}
& K=V A B_{p c} 1996_{m}=\mathrm{VAB} \text { per capita agropecuário médio regional em 1996; } \\
& \Phi=\mathrm{VAB}_{p c} 2010_{m}=\mathrm{VAB} \text { per capita agropecuário médio regional em } 2010 .
\end{aligned}
$$

No entanto, deve-se destacar que, segundo Piacenti (2012a) a diferença básica do IRC agro para o INC agro é que, neste, utiliza-se o VAB per capita de um único ano, ou seja, de forma estática, enquanto que, no $I R C_{\text {agror }}$ são usados, de forma comparativa, os valores do VAB per capita tanto do Estado quanto o VAB per capita médio da macrorregião de dois períodos. Dessa forma, mede-se o nível de desempenho econômico não apenas em um único ano, mas o seu desempenho econômico de forma dinâmica em dois momentos distintos, permitindo, assim, captar o valor do VAB per capita do estado e da região em análise ao longo de um período de tempo (PIACENTI, 2012a).

A seção subsequente explora o perfil agropecuário dos estados da Região Sul do Brasil ao procurar demonstrar o peso do setor em discussão em cada economia estadual.

\section{PERFIL AGROPECUÁRIO DOS ESTADOS DA REGIÃO SUL}

De acordo com Zylbersztajn e Neves (2000), desde meados dos anos 1980, a abertura comercial e a consolidação dos blocos econômicos trouxeram a realidade da globalização para dentro da economia brasileira transformando significativamente os padrões produtivos do país. Dado o contexto, evidencia-se a importância de analisar tais implicações na região Sul do Brasil. Para tanto, observa-se os números do VAB Total e do VAB Agropecuário nessa região, e de cada estado que a constitui.

Pela Tabela 1, verifica-se que todos os estados apresentaram crescimento no valor do VAB Total, bem como na evolução do VAB Agropecuário quando comparados os anos de 1996 e 2010, sugerindo que o acréscimo do VAB Total foi oriundo, também, da expansão do setor agropecuário ao longo do período analisado.

Tabela 1. Valor Adicionado Bruto $(\mathrm{VAB})^{1}$ total e agropecuário dos estados da Região Sul do Brasil (em milhões de reais) - 1996 e 2010

\begin{tabular}{l|c|c|c|c|c|c}
\hline \multirow{2}{*}{ ESTADOS } & \multicolumn{3}{|c|}{1996} & \multicolumn{3}{c}{2010} \\
\cline { 2 - 7 } & VAB Total $^{2}$ & $\%$ & VAB agro & VAB Total & $\%$ & VAB agro \\
\hline Paraná & $164.016,72$ & 35,4 & $13.615,44$ & $214.001,41$ & 34,9 & $18.137,15$ \\
\hline Rio G. do Sul & $197.463,59$ & 42,7 & $18.166,65$ & $250.324,85$ & 40,8 & $21.743,78$ \\
\hline Santa Catarina & $101.338,81$ & 21,9 & $8.309,78$ & $149.268,34$ & 24,3 & $10.003,94$ \\
\hline
\end{tabular}

Fonte: IBGE (2012).

${ }^{1}$ Valor Adicionado Bruto a preços básicos.

${ }^{2}$ Valores atualizados pelo IGP-DI para fevereiro de 2013. 
A identificação desse processo reflete a forte reação da agropecuária decorrente dos efeitos positivos da combinação entre expansão da economia mundial, elevação da cotação das commodities e câmbio desvalorizado, principalmente no período de 1990 a 2005. Além disso, o novo cenário de globalização dos mercados induziu o setor agropecuário à busca de mecanismos para a manutenção de sua competitividade, levando a uma procura crescente por maior eficiência nos processos produtivos dentro do âmbito do setor em estudo, devido, principalmente, ao aumento da concorrência internacional (MORETTO; RODRIGUES; PARRÉ, 2002).

Para tanto, o setor agropecuário vem experimentando a expansão para atividades com maior capacidade de agregação de valor, ou seja, o setor agroindustrial. Porém, o setor agropecuário também evolui ao acompanhar o setor industrial e de serviços, uma vez que o mesmo se apresenta como importante fornecedor de matéria-prima para o processamento ao mesmo tempo em que demanda e gera serviços (BULHÕES, 2007).

Segundo Hirschman (1985), os encadeamentos gerados entre os setores agropecuário, industrial e de serviços sugerem uma interdependência e assinalam inter-relacões, em que tudo depende de tudo, refletindo uma variedade de efeitos multiplicadores ou de transbordamento. Encadeamentos para trás se encarregam de enviar estímulos para setores que fornecem os insumos demandados por uma atividade qualquer, enquanto encadeamentos para frente levam ao estabelecimento de novas atividades que utilizam o produto da atividade sugerida (ALVES; FERRERA DE LIMA; RIPPEL, 2007).

Quanto à evolução do grau de importância da economia dos três estados no total da economia da Região Sul, observa-se que, entre eles, o Rio Grande do Sul obteve o maior VAB Total no ano de 2010 , perfazendo $40 \%$ do total da região. O Paraná segue com $35 \%$ do VAB regional, ficando Santa Catarina com $24 \%$ do $V A B$ total da região.

Ao analisar o grau de importância de cada estado no total da economia da Região Sul, verifica-se a trajetória da participação do $V A B$ total dos estados quando comparado ao VAB total da Região Sul, com destaque para a evolução de Santa Catarina. O avanço presenciado evidencia a condição de modernização da economia catarinense, o que é comprovado pelo aumento gradual da participação do estado na economia brasileira. Além disso, o resultado da produção agropecuária catarinense deve-se ao desempenho das atividades de produtos da lavoura temporária (fumo e cebola), bem como a silvicultura e a exploração florestal.

Como visto, o VAB Agropecuário de todos os estados do Sul do Brasil apresentou crescimento ao longo do período em estudo, indicando que $O$ acréscimo do VAB Total adveio, também, da evolução desse setor e, de certa forma, deixando evidente a importância do setor agropecuário para a economia da Região Sul em conjunto com os efeitos encadeadores proporcionados por esse setor.

De acordo com Conterato, Schneider e Waquil (2007), a dinâmica de desenvolvimento do Rio Grande do Sul vincula-se estreitamente com a trajetória 
da agricultura, e que esta relação não se desfez com o aprofundamento dos processos de mercantilização da sociedade como um todo e da própria agricultura, apenas metamorfoseou-se logo. Embora o estado tenha diminuído ao longo do período analisado sua participação no VAB da Região Sul e assista, conjuntamente com outros estados, ao aumento da participação do setor industrial e de serviços na sua economia, a produção primária ainda consiste na sua fonte básica de riqueza, ressaltando o vínculo histórico do estado com esse setor.

Em relação à população urbana e rural dos estados da Região Sul entre 1996 e 2010, salienta-se, inicialmente, que existem quatro componentes demográficos que podem provocar a mudança no número de pessoas em uma região: nascimentos, óbitos, emigração e imigração. Percebe-se pelos dados do IBGE (2012) que houve crescimento da população urbana na Região Sul e diminuição da população rural em todos os estados no período de 1996 a 2010.

Para Junqueira, Sterchile e Ferrera de Lima (2009), os principais indicadores de tal fenômeno são explicados pelos processos de migração das populações rurais para os centros urbanos em busca de melhores condições de trabalho, e pela diminuição dos postos de trabalho gerados pelos processos de produção agrícola moderno. A redução da população rural indica que os processos modernos de produção agrícola não proporcionaram, no período, condições para ocupar toda a população rural existente na região. Além disso, tais processos utilizam modernos insumos e mecanização agrícola, exigindo um menor número de empregados e estabelecendo um novo padrão para o mercado de trabalho rural.

Segundo Gasques et al. (2010), esse comportamento reflete inovações tecnológicas ocorridas nos sistemas de produção utilizados, introdução de novos produtos e mudanças na política trabalhista brasileira. Além disso, estudos relacionados à produtividade total dos fatores (PTF) demostram que o crescimento da agricultura brasileira tem se dado, principalmente, com base nos ganhos em produtividade e não com o aumento do uso de insumos, entre eles mão de obra.

De forma complementar, estudos revelam que, até 1995, a produção agrícola brasileira era impulsionada principalmente, pelo aumento do uso de insumos. Para Graziano da Silva (1998), esse foi um período no qual houve acentuado crescimento a partir de ocupações de terras em regiões novas como o Centro-Oeste. Também se caracterizou pela concessão de grandes subsídios ao crédito rural e por um padrão de crescimento no qual se introduzia de forma crescente a tecnologia na agricultura.

Essa mudança na estrutura produtiva foi um dos elementos motivadores do êxodo rural e, com isso, um grande fluxo migratório. Ao analisar os fatores de expulsão e atração da população para o Paraná, Carvalho e Waquil (2002) verificaram que as transformações pelas quais passou a economia paranaense atuariam expulsando a população do campo e atraindo-a para o meio urbano. Em suma, para Hobsbawm (1995, p. 284), essa alteração no perfil demográfico é a mudança social mais importante e de maior alcance na segunda metade do século $\mathrm{XX}$, e a "que nos isola para sempre do mundo do passado".

Antes de verificar e discutir o nível e o ritmo de crescimento agrícola da Região Sul, compreende-se, como necessário, o estudo do grau de concentração 
das atividades agrícolas no espaço em análise. A seção seguinte aborda essa concentração.

\subsection{A concentração da produção agrícola na Região Sul do Brasil}

Para melhor entender os padrões regionais do crescimento econômico agropecuário da Região Sul do Brasil, utilizou-se o cálculo do QL. Essa medida de especialização busca explicar o grau de concentração de atividades produtivas agrícolas selecionadas no espaço econômico em análise.

Em suma, segundo Almeida, Alves e Funk (2007), quando os produtos selecionados em determinada região apresentam QLs abaixo de 1, significa que a produção se direciona ao consumo e ao comércio interno, quando o QL for acima de 1 , significa que existe uma especialização por parte da região na produção de tal produto, e quando este QL ultrapassar 1.5, evidencia que tal produção se direciona ao mercado externo, ou seja, este produto ultrapassa as fronteiras da região. No entanto, se existe apenas um produto na região capaz de demonstrar um QL elevado, isto significa que existe uma dependência econômica, indicativo de uma situação delicada para a região.

Conforme resultados da Tabela 2, nota-se que o Paraná, tendo como base o ano de 2010, apresenta vantagem produtiva nas produções de café, feijão, milho, soja e trigo. O Rio Grande do Sul obteve estatísticas superiores à unidade na soja, sorgo e, expressivamente, em arroz, sugerindo que existe uma maior concentração dessas produções no conjunto de todas as outras, ou seja, o estado possui vantagem locacional nessas atividades no âmbito regional. O estado é o maior produtor de arroz, com $65,3 \%$ de participação na produção nacional do grão, apesar dos problemas observados nos últimos cinco anos com o volume de chuvas. Ao longo do período considerado, o Estado de Santa Catarina ganhou representatividade na produção de arroz, posicionando-se como o segundo produtor nacional do grão, além de manter sua vantagem na produção de feijão e de milho.

Tabela 2. Quociente Locacional por Estado do Sul do Brasil e por produto agrícola selecionado, 1996 - 2010

\begin{tabular}{|c|c|c|c|c|c|c|c|c|}
\hline \multirow{4}{*}{ ஜ } & ESTADOS & Arroz $^{1}$ & Café & Feijão & Milho & Soja & Sorgo & Trigo \\
\hline & Paraná & 0,08 & 1,94 & 1,17 & 1,16 & 1,13 & 0,05 & 1,29 \\
\hline & Rio G. do Sul & 2,26 & 0 & 0,33 & 0,60 & 1,01 & 2,56 & 0,80 \\
\hline & Santa Catarina & 0,98 & 0,01 & 2,54 & 1,64 & 0,34 & 0,09 & 0,31 \\
\hline \multirow{4}{*}{ 윰 } & ESTADOS & Arroz & Café & Feijão & Milho & Soja & Sorgo & Trigo \\
\hline & Paraná & 0,04 & 2,01 & 1,48 & 1,19 & 1,07 & 0 & 1,19 \\
\hline & Rio G. do Sul & 2,15 & 0 & 0,27 & 0,62 & 1,02 & 2,53 & 0,92 \\
\hline & Santa Catarina & 1,27 & 0 & 1,54 & 1,58 & 0,52 & 0 & 0,41 \\
\hline
\end{tabular}

${ }^{1}$ Como zona de referência para o calculo do QL adotou-se a Região Sul.

Fonte: Resultados da pesquisa com base em dados do SIDRA (2012). 
Ao analisar algumas atividades, ressalta-se que, em 2010, a produção de café e de trigo foi unicamente representativa para o Estado do Paraná e do Rio Grande do Sul, respectivamente. O Paraná possui uma área de zoneamento agrícola apta para a produção de café. No entanto, quanto à produção de trigo, percebe-se que esta atividade produtiva perde relativa importância ao longo do tempo. Segundo Vieira Filho, Campos e Ferreira (2005), com as transformações econômicas ocorridas, a produção de trigo deixa de ser um atrativo regional em termos de vantagens comparativas face ao mercado externo e a competição com melhores rendimentos em outras atividades. De fato, após a abertura comercial e o acordo do MERCOSUL, a forte competitividade externa abalou seriamente a atividade produtora de trigo no Brasil.

\section{NÍVEL E RITMO DE CRESCIMENTO ECONÔMICO AGROPECUÁRIO DOS ESTADOS DA REGIÃO SUL DO BRASIL}

O crescimento econômico agropecuário da Região Sul do Brasil ocorrido nas últimas duas décadas foi acompanhado de mudanças em sua estrutura de produção, como evidenciado anteriormente. Segundo Jank, Nassar e Tachinardi (2005), a década de 1990 pode ser descrita como a do choque de eficiência e de competitividade, resultante de um pesado ajuste que decorreu do fim do crédito rural, do forte endividamento dos produtores com o descasamento dos custos e preços, da abertura comercial e do controle da inflação, cenário contrário do presenciado na década de 1980.

Esses aspectos provocaram uma crise de rentabilidade no setor. A produção agropecuária e o setor de alimentação funcionaram como uma importante "âncora verde" do processo de estabilização da inflação (JANK; NASSAR; TACHINARDI, 2005). O contexto descrito solidificou o crescimento da indústria que levou o setor secundário a superar os demais setores em importância econômica e a posicionar o setor primário atrás do setor terciário (CARVALHO; WAQUIL, 2002).

Corroborando com os fatos elucidados, Nunes, Gomes e Ramos (2008) argumentam que o desenvolvimento tecnológico leva a uma separação das etapas do trabalho. Em virtude disso, a agricultura tende a perder participação na composição do PIB ao longo dos anos, uma vez que a separação/especialização das etapas do trabalho gera novas mercadorias e serviços, além de maiores quantidades.

Frente a essas transformações e ao perfil da Região Sul apresentado, faz-se necessário analisar o ritmo e o nível de crescimento econômico agropecuário dos estados dessa região. Para tanto, foram elaborados para cada estado dois conjuntos de indicadores: o $I N C_{\text {agro }}$ e o $I R C_{\text {agro }}$. Os resultados são apresentados na Tabela 3. 
Tabela 3. Classificação dos Estados conforme os indicadores selecionados

\begin{tabular}{|c|c|c|c|c|}
\hline ESTADOS & $\mathrm{INC}_{\mathrm{agro}}{ }^{1}$ & $\mathrm{IRC}_{\mathrm{agro}}{ }^{2}$ & $I R C_{\text {agro }}$ em \% & Classificação do IRC ${ }_{\text {agro }}{ }^{3}$ \\
\hline Paraná & 100,97 & 93,71 & $-6,29$ & Depressivo \\
\hline Rio G. do Sul & 107,93 & 103,86 & 3,86 & Recessivo \\
\hline Santa Catarina & 84,95 & 103,01 & 3,01 & Recessivo \\
\hline \multicolumn{5}{|c|}{$\begin{array}{l}1 \text { O INC } \text { agro da Região Sul relativo ao ano de } 2010 \text { foi de } 161,49 . \\
{ }^{2} \text { O IRC }\end{array}$} \\
\hline
\end{tabular}

Observa-se que o $I N C_{\text {agro }}$ para cada um dos estados da Região Sul, relativo a 2010, situou-os abaixo da média regional. Ou seja, os resultados demostraram que os três estados apresentaram um VAB per capita agropecuário inferior à média regional, sendo classificados como economicamente deprimidos, bem como, sinalizando para uma queda da representatividade da Região Sul no setor agropecuário nacional.

A instabilidade na produção agropecuária acaba repercutindo no conjunto da economia estadual por essa estar fortemente interligada a outros setores da sua matriz produtiva. Dessa forma, quando a agropecuária apresenta um bom desempenho, outros setores são indiretamente beneficiados (FOCHEZATTO; GRANDO, 2011). Segundo estudo realizado por Alves (2007), para o Rio Grande do Sul, o baixo crescimento econômico agropecuário evidencia a desestruturação da produção agrícola em termos regionais.

De acordo com a FEE (2012), a economia gaúcha é dependente da agropecuária. $E$, ao impactar, direta e indiretamente, parcela tão significativa do $V A B$, o desempenho da agropecuária torna-se decisivo na explicação da evolução da economia do estado. Estudos demonstram que, nos últimos 11 anos, em dez deles vigorou a máxima de que, quando o produto da agropecuária gaúcha cresce acima da taxa do PIB gaúcho, o PIB do estado cresce acima do PIB brasileiro, e, quando ocorre o contrário, o PIB do Rio Grande do Sul expande-se menos que o nacional.

O transbordamento desse resultado reforça a argumentação de Carvalho (2002) ao afirmar que, o comércio agrícola brasileiro, no agregado, passou para a situação de vulnerabilidade, uma vez que aumentou sua eficiência num mercado em decadência, haja vista que $30 \%$ do total das exportações brasileiras são procedentes de um setor de posicionamento desfavorável como a agricultura.

No caso do Paraná, segundo Bulhões (2007), embora a pauta de produtos agrícolas seja bastante diversificada, existe uma especialização em torno do cultivo da soja, que juntamente com o milho, faz parte do complexo de produção junto a agroindústrias. Isso leva a considerar que modificações abruptas em sua produção, quer sejam por ordem natural (alterações climáticas) ou econômica (modificação nos preços) terão reflexos tanto nos produtores quanto nos integrantes de todo o complexo.

Em relação ao $I R C_{\text {agro }}$ (Tabela 3), todos os estados apresentaram ritmo de crescimento agrícola acima da média da Região Sul. Porém, de acordo com as 
faixas percentuais de classificação propostas por Piacenti (2012a) para o IRC, Rio Grande do Sul e Santa Catarina apresentam um ritmo de crescimento recessivo e o Estado do Paraná um ritmo depressivo. Em relação ao Rio Grande do Sul, Fochezatto e Grando (2011) afirmam que a agricultura gaúcha possui uma dinâmica peculiar, dado o efeito que o clima tem sobre sua produção. Isso faz com que as oscilações na trajetória da agricultura determine e impacte, direta e indiretamente, as oscilações do PIB estadual, sinalizando uma economia significativamente dependente da agropecuária.

O impacto do clima sobre a produção agrícola do estado, e a consequente oscilação do PIB estadual, apresenta uma expressividade significativa apontada por estudos. Em função de duas estiagens sucessivas, verificaram-se as respectivas quedas de 10,6\% e de 17,4\% na agropecuária gaúcha nos anos de 2004 e 2005, que acabaram por afetar negativamente toda a economia, fazendo com que o crescimento do PIB estadual fosse menor que o nacional nos dois anos (FEE, 2012). Ao analisar os efeitos da estiagem de 2008 na economia do Rio Grande do Sul, Fochezatto e Grando (2011) reafirmam que a incidência de estiagem é um fator fundamental na definição do desempenho da economia do Rio Grande do Sul, o problema é que se trata de um evento exógeno e aleatório.

O Estado do Paraná, embora esteja na faixa de crescimento econômico depressivo, também apresenta um ritmo de crescimento acima da média regional. Para Farjado (2008) e Braun et al. (2012), o Paraná sempre acompanhou o crescimento da agricultura no conjunto do país e o desempenho da agroindústria paranaense. Independentemente da crise financeira internacional ocorrida na década de 2000, tem alavancado o crescimento das vendas industriais paranaenses.

A importância do agronegócio para esse estado é confirmada não somente em termos do valor da produção, mas também em função das relações inter e intrasetoriais que representa. Por exemplo, a agricultura mostra-se como um setor importante na oferta de insumos e a indústria alimentar representa o conjunto dos setores demandantes de insumos mais importantes, conforme destaca Simm e Alves (2005).

O presente estudo permitiu evidenciar que a nova configuração regional do agronegócio confere à Região Sul do país a busca de diversificação e de modernização do setor agrícola. Principalmente, tendo em vista o atendimento de mercados intensamente influenciados pelo crescimento da demanda interna, com a consolidação da estabilidade monetária, e pela continuidade da liberalização comercial. Haja vista que, a fronteira física rural está esgotada há mais de duas décadas na Região Sul do Brasil, implicando a abertura de novas frentes de expansão.

\section{CONSIDERAÇÕES FINAIS}

Objetivou-se, neste artigo, analisar o perfil e o crescimento econômico agropecuário dos estados da Região Sul do Brasil, entre os anos de 1996 e 2010. 
Esse período é caracterizado por um contexto que altera significativamente a postura produtiva brasileira, de modo que a produção de produtos básicos, principalmente commodities, perde importância, sendo superada pela produção manufatureira.

O estudo permitiu verificar que o processo de crescimento econômico agrícola da Região Sul, considerando o VAB Agropecuário, foi dinâmico, havendo acréscimo do $V A B$ Agropecuário em todos os estados. A análise dos indicadores baseados no VAB per capita agropecuário possibilitou inferir que o nível de crescimento dos estados da Região Sul caracteriza-se como de economia agrícola deprimida, reflexo do processo de "descommoditização" presente no setor agropecuário e potencializado na década de 1990, bem como o desempenho das "novas fronteiras agrícolas brasileiras" como, por exemplo, o Centro-Oeste ampliado (COA).

Em uma análise complementar, o indicador do ritmo de crescimento econômico agrícola permitiu classificar o Estado de Santa Catarina e do Rio Grande do Sul como de crescimento agrícola recessivo, caracterizando uma redução expressiva das atividades agrícolas. O Estado do Paraná enquadra-se na faixa de crescimento depressivo, cujo desempenho agrícola, entre 1996 e 2010, foi negativo.

Torna-se pertinente salientar que, embora a década de 1990 tenha apresentado alguns entraves para o desempenho do setor agropecuário, a expansão do agronegócio brasileiro baseou-se, principalmente a partir deste período, em ganhos de eficiência relacionados à incorporação de tecnologia com o objetivo de aumentar a produtividade dos fatores de produção.

Por fim, este estudo gerou informações relevantes sobre a configuração geoeconômica dos estados da Região Sul do Brasil, dando subsídios para a formação de estratégias para o crescimento e desenvolvimento regional. Ao destacar uma expressiva relação de cada estado da Região Sul com o setor agropecuário, sugere-se, para estudos posteriores, uma maior discussão acerca da configuração rural-urbano no espaço em destaque.

\section{REFERÊNCIAS}

ALMEIDA, C. S.; ALVES, L. R.; FUNK, F. Análise das inter-relações setoriais do Corede Vale do Rio Pardo/RS-Brasil. I $n$ : $\mathrm{V}$ JORNADAS INTERDISCIPLINARIAS DE ESTUDIOS AGRARIOS Y AGROINDUSTRIALES, Buenos Aires, 2007. Anais...Buenos Aires: Jornadas Interdisciplinarias de Estudios Agrarios y Agroindustriales, 2007.

ALVES, L. R. Indicadores de localização, especialização e estruturação regional. In: PIACENTI, C. A.; FERRERA DE LIMA, J. (org). Análise Regional: metodologias e indicadores. Curitiba: Edição Camões/ Michelotto, p. 33-50, 2012.

ALVES, L. R.; FERRERA DE LIMA, J.; RIPPEL, R. Encadeamento produtivo, localização e a associação geográfica dos ramos industriais nas microrregiões do 
Paraná. In: STADUTO, J. A. R.; BRAUN, M. B. S.; SILVA, C. L.; ROCHA JUNIOR, W. F. (Org.). Agronegócio e Desenvolvimento Regional: reflexões sobre a competitividade das cadeias de produção paranaense. Cascavel: Edunioeste, p. 231-254, 2007.

ALVES, T. W. Crescimento e concentração da produção agrícola no Rio Grande do Sul de 1970 a 1996. Perspectiva econômica, v. 3, n. 2, p. 1-26, 2007.

BRAUN, M. B. S.; CARDOSO, R. D.; DAHMER, V. DE S.; RINALDI, R. N. Consolidação e perspectivas da agroindústria paranaense em relação ao MERCOSUL: uma análise de 1999 a 2009. Revista Paranaense de Desenvolvimento, Curitiba, n.122, p. 221-240, 2012.

BULHÕES, R. O peso da soja na economia do Estado do Paraná. In: V ENCONTRO DE ECONOMIA PARANAENSE, Curitiba, 2007. Anais...Curitiba: ECOPAR, 2007.

CARVALHO, M. A. de. Comércio agrícola e vulnerabilidade externa brasileira. Agricultura em São Paulo, São Paulo, v. 49, n. 2, p. 55-69, 2002.

CARVALHO, S. C. de.; WAQUIL, P. D. Os condicionantes econômicos Internos das migrações no Paraná entre 1970 e 1996. In. CUNHA, M. S.; SHIKIDA, P. F. A.; ROCHA JÚNIOR, W. F. (org). Agronegócio paranaense: potencialidades e desafios. Cascavel: Edunioeste, p. 125-144, 2002.

CONTERATO, M. A.; SCHNEIDER, S.; WAQUIL, P. D. Desenvolvimento rural no Estado do Rio Grande do Sul: uma análise multidimensional de suas desigualdades regionais. REDES, Santa Cruz do Sul, v. 12, n. 2, p. 163-195, 2007.

DINIZ, C. C. A dinâmica regional recente da economia brasileira e suas perspectivas. Brasília: IPEA, 1995.

FAJARDO, S. Complexo agroindustrial, modernização da agricultura e participação das cooperativas agropecuárias no Estado do Paraná. Caminhos da Geografia, Uberlândia: UFU, v.9, n.27, p. 31-44, 2008.

FEE - Fundação de Economia e Estatística Siegfried Emanuel Heuser. Carta de conjuntura. Porto Alegre, Ano 21, n. 1, 2012.

FERRERA DE LIMA, J.; EBERHARDT, P. H. de C. Mesorregião Grande Fronteira do MERCOSUL: perfil locacional do desenvolvimento regional. REDES, Santa Cruz do Sul, v. 15, n. 2, p. 134-151, 2010.

FERRERA DE LIMA, J.; KOELER, W. S. Funções da agricultura no processo de desenvolvimento do Brasil: algumas considerações preliminares sobre o período de 1930-1945. Archetypon, Rio de Janeiro, v. 06, n.18, p. 49-66, 1998. 
FOCHEZATTO, A.; GRANDO, M. Z. Efeitos da estiagem de 2008 na economia do Rio Grande do Sul: uma abordagem multissetorial. Ensaios FEE, Porto Alegre, v. 32, n. 1, p. 137-160, 2011.

GASQUES, J. G.; BASTOS, E. T.; BACCHI, M. R. P.; VALDES, C. Produtividade total dos fatores e transformações da agricultura brasileira: análise dos dados dos censos agropecuários. In. GASQUES, J. G.; VIEIRA FILHO, J. E. R.; NAVARRO, Z. (Org). A agricultura brasileira: desempenho, desafios e perspectivas. Brasília: IPEA, p. 19-44, 2010.

GRAZIANO DA SILVA, J. A nova dinâmica da agricultura brasileira. 2a Ed., Universidade Estadual de Campinas (UNICAMP), Instituto de Economia, 1998.

HADDAD, P. R. Métodos de análise de setores-chave e de complexos industriais. In: HADDAD, P. R. (Org.). Economia regional: teorias e métodos de análise. Fortaleza: BNB/ETENE, 1989, p. 399-426.

HIRSCHMAN, A. Desenvolvimento por efeitos cadeia: uma abordagem generalizada. In: SORJ, B. (Org). Economia e movimentos sociais na América Latina. São Paulo: Brasiliense, p. 87-112, 1985.

HOBSBAWM, E. A Era dos Extremos: o Breve Século XX (1914-1991). São Paulo: Companhia das Letras, 1995.

IBGE - Instituto Brasileiro de Geografia e Estatística. Banco de dados agregados SIDRA. Disponível em: <www.sidra.ibge.gov.br/bda/>. Acesso em: 10 out. 2012.

IPEADATA - Instituto de Pesquisa Econômica Aplicada. Dados agregados. Disponível em <http:// www.ipeadata.gov.br>. Acesso em: 13 out. 2012.

JANK, M. S.; NASSAR, A. M.; TACHINARDI, M. T. Agronegócio e comércio exterior. Revista USP, São Paulo, n.64, p. 14-27, 2005.

JUNQUEIRA, C. P.; STERCHILE, S. P. W.; FERRERA DE LIMA, J. O crescimento econômico agrícola dos Estados da Região Sudeste do Brasil - 1995/2005. Organizações Rurais \& Agroindustriais, Lavras, v.11, n.3, p. 407-419, 2009.

LOURENÇO, G. M. Agronegócio no Paraná: oportunidades e ameaças. In. CUNHA, M. S.; SHIKIDA, P. F. A.; ROCHA JÚNIOR, W. F. (org). Agronegócio paranaense: potencialidades e desafios. Cascavel: Edunioeste, p. 11-32, 2002.

MORETTO, A. C.; RODRIGUES, R. L.; PARRÉ, J. L. Tendências do agronegócio no Paraná: 1980 a 1995. In. CUNHA, M. S.; SHIKIDA, P. F. A.; ROCHA JÚNIOR, W. F. (org). Agronegócio paranaense: potencialidades e desafios. Cascavel: Edunioeste, p. 33-56, 2002. 
NUNES, S. P; GOMES, E. J.; RAMOS, C. E. P. A intervenção na economia diante do processo de centralização do capital. Vizivali em Revista, v. 06, p. 130-150, 2008.

PAIVA, C. A. N. Desenvolvimento regional, especialização e suas medidas. Indicadores Econômicos FEE. Porto Alegre, vol. 34, n.1, p. 89-102, 2006.

PIACENTI, C. A. O potencial de desenvolvimento endógeno dos municípios paranaenses. Curitiba: Camões, $2012 \mathrm{~b}$.

PIACENTI. C. A. Indicadores de desenvolvimento endógeno. In: PIACENTI, C. A.; FERRERA DE LIMA, J. (org). Análise Regional: metodologias e indicadores. Curitiba: Edição Camões/ Michelotto, p. 95-132, 2012a.

SIMM, E. B.; ALVES, A. F. Concentração espacial da agroindústria paranaense durante a década de 1990. In: XLIII CONGRESSO BRASILEIRO DE ECONOMIA E SOCIOLOGIA RURAL, Ribeirão Preto, 2005. Anais...Ribeirão Preto: SOBER, 2005.

SPEROTTO, L.; SOUZA, N. J. O desenvolvimento econômico da Região Noroeste do Rio Grande do Sul, 199/2000. Estudos do CEPE, Recife, n. 22, p. 107-130, 2005.

VIEIRA FILHO, J. E. R.; CAMPOS, A. C.; FERREIRA, C. M. de C. Abordagem alternativa do crescimento agrícola: um modelo de dinâmica evolucionária. Revista Brasileira de Inovação, v. 4, n. 2, p. 425-476, 2005.

ZYLBERSZTAJN, D.; NEVES, M. F. Economia e gestão dos negócios agroalimentares. São Paulo: Pioneira, 2000.

Submetido em 19/07/2013

Aprovado em 28/04/2015

Sobre os autores

Isabela Barchet

Economista, doutoranda no Programa de Pós-Graduação em Desenvolvimento Regional e agronegócio da UNIOESTE/Campus de Toledo.

E-mail: isabelabarchet@hotmail.com

Jandir Ferrera de Lima

Ph.D. em Desenvolvimento Regional pela Université du Québec a Chicoutimi (UQAC)/Canadá.

Professor Adjunto do Programa de Pós-Graduação em Desenvolvimento Regional e Agronegócio da UNIOESTE/Campus de Toledo.

E-mail: jandir@unioeste.br 